\title{
Contexto escolar e indicadores educacionais: condições desiguais para a efetivação de uma política de avaliação educacional'
}

Maria Teresa Gonzaga Alves"

José Francisco Soares"

\section{Resumo}

A introdução do Índice de Desenvolvimento da Educação Básica (Ideb) pelo governo federal representou uma mudança significativa na forma como a educação passou a ser acompanhada no Brasil. 0 Ideb é o indicador de qualidade desenvolvido para avaliar a educação oferecida no país e em cada unidade da federação, município e escola pública. Ele serve também para acompanhar a melhoria da qualidade educacional segundo metas preestabelecidas. Seu uso para essas finalidades tem suscitado debates sobre o tipo de política de responsabilização que o indicador engendra. Argumenta-se, neste artigo, que o Ideb coloca foco em resultados finalísticos, sem considerar as condições que propiciam a obtenção de tais resultados. 0 trabalho analisa a relação entre o indicador e o contexto escolar, considerando para tal o perfil de seus alunos e as características do estabelecimento de ensino. A análise empírica utiliza dados da Prova Brasil, do Censo Escolar e do próprio Ideb, por meio de modelos de regressão linear múltipla. Os resultados mostram que as escolas que atendem a alunos de menor nível socioeconômico, como esperado, têm piores resultados, mesmo com o controle de outras características. Para essas escolas, é muito mais difícil elevar o valor do indicador. Além disso, as condições de infraestrutura e de complexidade da instituição também guardam relação com o Ideb. Por fım, os resultados indicam que são necessárias políticas de superação dessas limitações e que tais condições não podem ser ignoradas na análise do Ideb.

\section{Palavras-chave}

Avaliação educacional - Contexto escolar - Ensino fundamental.

I- Os autores agradecem ao Conselho Nacional de Desenvolvimento Científico e Tecnológico (CNPq) 0 auxilio concedido à pesquisa, o qual possibilitou este artigo.

II- Universidade Federal de Minas Gerais, Belo Horizonte, MG, Brasil.

Contatos: mtga@ufmg.br;

francisco-soares@ufmg.br 


\title{
School context and educational indicators: unequal conditions for the implementation of an education assessment policy
}

\author{
Maria Teresa Gonzaga Alves" \\ José Francisco Soares"
}

\begin{abstract}
The introduction by the federal government of the Basic Education Development Index (Ideb in the Portuguese acronym for Índice de Desenvolvimento da Educação Básica) represented a significant change in the way in which education is followed in Brazil. Ideb is the quality indicator developed to evaluate the education offered in this country and by each unit of the Federation, municipality, and public school. It also allows following the improvement in the quality of education according to preestablished goals. Its use for these purposes has been fuelling debates about the kind of policy of accountability that the indicator creates. It is argued in this article that Ideb puts focus on end results, without taking into account the conditions that have contributed to obtaining such results. The work analyzes the relations between this indicator and the school context, considering the profile of the pupils and the characteristics of the teaching institution. The empirical study makes use of data from the Prova Brasil, from the School Census and from Ideb itself through models of multiple linear regression. The results show that the schools that cater for pupils of a less privileged socioeconomic background exhibit, as expected, poorer results even when controlled for other features. These schools find it much more difficult to elevate the value of the indicator. Besides, infrastructure conditions and the complexity of the institutions are also correlated with Ideb. Lastly, the results indicate that there is a need for policies to overcome these limitations and that these conditions cannot be ignored in the analysis of the Ideb.
\end{abstract}

\section{Keywords}

Educational assessment - School context - Fundamental education.

I- The authors acknowledge the support of the Brazilian National Council of Scientific and Technological Development (CNPq), which made this article possible.

II- Universidade Federal de Minas Gerais, Belo Horizonte, MG, Brasil.

Contatos:mtga@ufmg.br;

francisco-soares@ufmg.br 
Este trabalho analisa a relação entre o contexto escolar - descrito pelo perfil dos alunos e pelas características da escola - e a qualidade educacional aferida pelo Índice de Desenvolvimento da Educação Básica (Ideb). Esse indicador foi introduzido na política educacional pelo Plano de Metas Compromisso Todos pela Educação (BRASIL, 2007). Ele é calculado, a cada dois anos, pelo Instituto Nacional de Estudos e Pesquisas Educacionais Anísio Teixeira (Inep) do Ministério da Educação (MEC), combinando dados de rendimento escolar - obtidos pelo Censo Escolar - com dados do desempenho dos alunos nas avaliações externas nacionais. Por meio do Ideb, o governo sinaliza para toda a sociedade que um sistema de ensino, para ter qualidade, deve garantir o aprendizado de seus alunos com uma trajetória educacional regular, sem reprovações (FERNANDES, 2007).

A introdução do Ideb se deu a partir da hipótese de que professores, diretores e gestores educacionais reagiriam a cobranças de resultados por parte da sociedade, melhorando a eficácia de seus processos internos e, consequentemente, a qualidade do ensino (FERNANDES; GREMAUD, 2009). Contudo, tal hipótese não leva em conta o fato de que os resultados escolares são fortemente associados à origem social e cultural dos alunos matriculados nas escolas (COLEMAN et al., 1966; BOURDIEU; PASSERON, 2008). Estudos educacionais mostram, também, que a melhoria no nível de desempenho dos alunos pode ser obtida ao custo do aumento da desigualdade entre grupos de alunos dentro das mesmas escolas (BRYK; LEE, 1989; FRANCO et al., 2007). Ou seja, práticas que melhoram a qualidade educacional média de um estabelecimento de ensino podem ter como efeito perverso o aumento da desigualdade entre alunos discriminados por raça/cor, gênero e outras variáveis sociodemográficas (SOARES; ALVES, 2003).

0 presente trabalho aborda a complexa relação entre o valor do Ideb da escola e suas características contextuais definidas pelo perfil de seus alunos e pelas condições da oferta escolar. Para tanto, faz uso dos dados da Prova Brasil, do Censo Escolar e do Ideb referentes às escolas públicas de ensino fundamental de todo o Brasil que possuem essas informações divulgadas pelo Inep. 0 texto está estruturado em quatro partes, além desta introdução. Inicialmente, será feita uma breve revisão sobre estudos anteriores a respeito das avaliações educacionais que culminaram com a introdução do Ideb, e sobre a presença desse indicador na pesquisa educacional recente. Na abordagem analítica, será exposto o modelo conceitual e sua operacionalização empírica. Em seguida, serão apresentados os resultados, os quais serão sumarizados e discutidos na última seção.

\section{Estudos anteriores}

As avaliações educacionais externas em larga escala são uma realidade no país desde a década de 1990, com a implantação do Sistema de Avaliação da Educação Básica (Saeb) pelo Inep. ${ }^{1}$ A consolidação do Saeb em nível nacional possibilitou que os sistemas de ensino pudessem ser avaliados e comparados quanto ao aprendizado de seus alunos, e não apenas quanto à capacidade de atendimento por meio da expansão da rede de ensino (OLIVEIRA; ARAÚJO, 2005). Assim, os resultados do Sistema, divulgados bianualmente até a edição de 2005, propiciaram a produção de um rico diagnóstico sobre a qualidade da educação ofertada pelas escolas brasileiras segundo grandes unidades amostrais: regiões, Estados, redes de ensino, dependências administrativas e localizações urbanas ou rurais. Eles subsidiaram também o desenvolvimento de pesquisas - até então raras no país - sobre o efeito das escolas e os fatores associados à eficácia do ensino (ALVES; FRANCO, 2008). Entretanto, apesar do grande esforço para a disseminação desses resultados por parte do Inep e do MEC, não havia muita repercussão do Saeb nos municípios e nas

1- Não é nosso objetivo fazer uma revisão da literatura sobre os sistemas de avaliação, tema amplamente coberto pela literatura especializada. Citam-se, por exemplo, Bonamino e Franco (1999) e Bonamino e Sousa (2012). 
escolas que forneciam as informações primárias por meio de seus alunos, porque eles não eram representados como unidades isoladas na avaliação nacional (COTTA, 2001).

Tal cenário mudou com a reestruturação do Saeb a partir de 2005, quando o Sistema passou a ser composto por duas avaliações externas: a Avaliação Nacional da Educação Básica (Aneb), que manteve basicamente as mesmas características da avaliação amostral realizada até 2003; e a Avaliação Nacional do Rendimento Escolar (Anresc), conhecida como Prova Brasil, que avalia as escolas públicas de forma quase censitária. Essa última passou a contemplar nominalmente os resultados dos estabelecimentos de ensino e dos municípios. Antes, apenas os Estados e alguns poucos municípios que já haviam desenvolvidos seus sistemas próprios de avaliação - como em São Paulo, no Rio de Janeiro, em Minas Gerais, no Ceará e em mais alguns outros - conheciam o desempenho médio dos alunos matriculados nas escolas de suas respectivas redes de ensino.

Em 2007, introduziu-se outra novidade importante no uso das avaliações externas nacionais. Os resultados do Saeb e da Prova Brasil, em conjunto com uma medida de rendimento fornecida pelo Censo Escolar, foram sintetizados no Ideb. Esse novo indicador - calculado para os anos iniciais do ensino fundamental, os anos finais do ensino fundamental e o ensino médio - foi criado para medir de forma objetiva a qualidade da educação básica, conforme os termos do Decreto ${ }^{\circ}$ 6.094, que o introduziu:

Art. $3^{\circ}$ - A qualidade da educação básica será aferida, objetivamente, com base no Ideb, calculado e divulgado periodicamente pelo Inep, a partir dos dados sobre rendimento escolar, combinados com o desempenho dos alunos, constantes do censo escolar e do Sistema de Avaliação da Educação Básica - Saeb, composto pela Avaliação Nacional da Educação Básica - Aneb e a Avaliação Nacional do Rendimento Escolar (Prova Brasil).
Parágrafo único. O Ideb será o indicador objetivo para a verificação do cumprimento de metas fixadas no termo de adesão ao Compromisso. (BRASIL, 2007, grifos nossos)

Para Reynaldo Fernandes (2007, p. 8), Presidente do Inep na gestão que introduziu o Ideb, o indicador

possui a vantagem de ser de fácil compreensão, simples de calcular, aplicável às escolas e explícito em relação à "taxa de troca” entre probabilidade de aprovação e proficiência dos estudantes.

Em um único número, expresso na escala de zero a 10, ele traduz a qualidade da educação e permite comparar as unidades avaliadas escolas, redes e sistemas estaduais e municipais de ensino -, bem como acompanhar a evolução do indicador ao longo do tempo. De acordo com o governo federal, o Ideb assume o papel de indutor de políticas para melhoria da educação, por meio de termo de adesão voluntária dos municípios e Estados ao Plano de Metas Compromisso Todos pela Educação. As metas desse plano visam a que Estados, municípios e escolas contribuam, em conjunto, para que o Brasil atinja um patamar educacional equivalente ao dos países desenvolvidos até 2022, ano do bicentenário da Independência. Em termos numéricos, isso significa obter, nos anos iniciais do ensino fundamental, um Ideb igual a 6,0 na média nacional, tendo como referência o valor inicial obtido em 2005, que foi de 3,8.

Desde 2007, quando o Ideb passou a ser calculado, já foram divulgadas quatro edições, referentes aos anos de 2005, 2007, 2009 e 2011. De acordo com os valores das metas do Ideb publicados pelo Inep, o país avançou em todos os níveis de ensino. Nos anos iniciais do ensino fundamental, o Ideb, que era de 3,6 em 2005, ultrapassou as metas criadas para os anos seguintes (obteve valores de 4,2, 4,6 e 5,0, em 2007, 2009 e 2011, respectivamente). Nos anos 
finais do ensino fundamental, sua evolução foi menor, mas também ultrapassou as metas (valores de 3,5, 3,8, 4,0 e 4,1, respectivamente). Já no ensino médio, o indicador também evoluiu na média, mas de forma bem menos expressiva do que nos níveis anteriores (3,4, 3,5, 3,6 e 3,7, respectivamente). Embora aparentemente esses valores possam ser considerados muito baixos, vale frisar que os pequenos incrementos obtidos no período representam grandes avanços, devido às peculiaridades envolvidas no cálculo do Ideb. ${ }^{2}$

A aparente simplicidade do Ideb - isto é, a escala de zero a 10 similar à de um boletim escolar e as metas criadas para cada unidade avaliada - facilitou sua rápida aceitação, especialmente na imprensa, entre os formuladores de políticas públicas e gestores educacionais. Inegavelmente, o Ideb tornou-se muito influente no debate educacional, haja vista a inclusão do indicador na proposta do Plano Nacional da Educação (PNE) para o atual decênio (BRASIL, 2010). No longo processo de negociação do PNE que se arrastou até 2012, a inclusão das metas do Ideb no texto praticamente não foi questionada comparativamente ao intenso debate que se deu em torno do financiamento da educação.

0 Ideb também conquistou legitimidade junto a uma parte do público acadêmico, ao mesmo tempo em que recebeu fortes críticas de pesquisadores. Em geral, seus apoiadores são da área da economia e os críticos são de origem mais educacional, refletindo uma tensão entre valores muito distintos (ALMEIDA, 2008; SETUBAL, 2010; SOUSA; OLIVEIRA, 2010). Por um lado, o Ideb é visto como uma modalidade de accountability (ou responsabilização) apropriada ao sistema educacional descentralizado vigente no país. Nessa perspectiva, o indicador e suas metas proporcionariam incentivos para que as escolas e os gestores se esforcem para melhorar simultaneamente o desempenho e o rendimento dos alunos, elevando, assim, a qualidade educacional (FERNANDES; GREMAUD, 2009).

2- Devido à metodologia do cálculo do Ideb, seus valores típicos raramente ultrapassam os limites abaixo de 3 ou acima de 6, conforme explicado por Soares (2011).
De outro lado, na literatura educacional, critica-se o Ideb como uma medida de qualidade da educação e questionam-se suas consequências para as escolas. Freitas (2007), por exemplo, considera o indicador como uma política de responsabilização unilateral que exclui as escolas ao mesmo tempo em que as estigmatiza. Para o autor, o Ideb não é referência de qualidade da educação, entre várias razões, porque ele não reflete a relação custo aluno/qualidade e também não é sensível às desigualdades sociais. De forma análoga, Sousa e Oliveira (2010) alertam para o uso do Ideb como uma simplificação a padrões educacionais desejáveis de problemas educativos mais complexos.

A despeito disso, reconhece-se que a ausência de consequências mais duras para as escolas associadas às metas do Ideb torna o indicador um tipo de responsabilização branda (BONAMINO; SOUSA, 2012). A divulgação de resultados por Estados, municípios e escolas, e as metas criadas para cada um deles não envolvem prêmios ou sanções, como ocorre em alguns Estados e municípios que possuem sistemas próprios de avaliação - por exemplo, Ceará, Pernambuco e São Paulo (BROOKE; CUNHA, 2011; FERRAZ, 2009).

Além das discussões sobre aspectos político-ideológicos associados ao Ideb, há uma crescente produção de estudos que analisam os resultados obtidos por municípios ou escolas, bem como a evolução do Ideb entre edições, considerando contextos territoriais, diferenças sociais e econômicas (ERNICA; BATISTA, 2011; GOUVEIA; SOUZA; TAVARES, 2009; MACHADO-SOARES et al., 2011; PADILHA et al., 2012). ${ }^{3}$

0 Ideb obtido pelos municípios foi analisado pela organização não governamental Todos Pela Educação (2010), e os resultados desqualificam os rankings de municípios segundo o Ideb, os quais, entretanto, continuam sendo sistematicamente produzidos e divulgados pela

3- 0 Ideb aparece em inúmeros trabalhos nos encontros da área, tais como: Associação Nacional de Pós-Graduação e Pesquisa em Educação (Anped), Associação Nacional de Política e Administração da Educação (ANPAE) e Associação Brasileira de Avaliação Educacional (ABAVE). 
mídia. 0 estudo mostra que alguns municípios podem atingir valores de Ideb acima da média nacional, mas com resultados bons apenas para parte dos alunos matriculados nas melhores escolas. Ou seja, as disparidades entre escolas dentro do mesmo município e da mesma rede de ensino não podem ser negligenciadas.

Também com foco nos municípios, Padilha et al. (2012) encontram as piores médias do Ideb principalmente nas metrópoles e nas cidades do litoral do Nordeste, o que se explicaria pelos efeitos negativos da segregação urbana no acirramento das desigualdades educacionais. Entretanto, os autores observam algumas exceções, sobretudo no Estado do Ceará. Também ali, Vidal e Vieira (2011) constatam que o Ideb é incondicionalmente aceito pelos gestores municipais, que o têm como norteador das políticas municipais de educação. 0 Ceará possui uma das mais longas experiências de adoção de política de responsabilização educacional no país, o que explicaria esse comprometimento entre os gestores do Estado (BROOKE; CUNHA, 2011).

Estudos sobre o próprio Ideb - sua composição interna e os fatores que impactam sobre seu cálculo - são ainda escassos. Esse tipo de análise é importante porque o Ideb, assim como qualquer outro indicador de natureza composta, exprime modelos que devem ter fundamentação teórica e correspondência com a realidade empírica. Entretanto, todos os indicadores desse tipo encerram certa dose de arbitrariedade e precisam de tempo e experimentação para que se possa avaliar sua consistência. Segundo Soares (2011), o cálculo do Ideb envolve escolhas que implicam consequências importantes na interpretação de seus valores. Assim, o equilíbrio ótimo entre desempenho e aprovação para elevar a média do Ideb pode ter como efeito perverso o aumento da desigualdade entre escolas e, principalmente, dentro das escolas, por meio da segregação de alunos com desempenho mais fraco.

0 conjunto desses estudos deixa subjacente certa tensão entre resultados e metas propostos pelo Ideb e as condições efetivas para a realização dessa política educacional, bem como os problemas do próprio indicador. 0 economista Amartya Sen (2009) oferece pistas para tratar desse dilema com a distinção entre resultados finalísticos e resultados globais (culmination and comprehensive outcomes). 0 Ideb se associa à ideia de resultados finalísticos, mas não fazem parte de sua justificativa os processos por meio dos quais os resultados foram obtidos. Resultados globais compreenderiam também os processos, os meios. Análises de resultados de políticas apenas por indicadores finalísticos nem sempre se traduzem em efeitos socialmente justos. Em educação, isso reflete a ausência de equidade na análise das políticas no setor. Um sistema educacional é considerado equitativo se a distribuição do desempenho dos grupos de alunos definidos por suas características sociais, de gênero ou raciais, por exemplo, é equivalente à distribuição total dos alunos (SOARES, 2006). A busca pela equidade se traduz em políticas e práticas educacionais que minimizem, nas escolas, as desigualdades econômicas e sociais existentes entre os alunos (DUBET, 2004).

Impõe-se, portanto, a necessidade de distinguir entre a descrição que o Ideb apresenta sobre a qualidade da educação e a explicação dos fatores que impactam no resultado sintetizado pelo indicador, principalmente no nível da escola. A intenção deste trabalho é contribuir nessa direção.

\section{Abordagem analítica}

Como exposto, o objetivo aqui é analisar o Ideb da escola considerando simultaneamente as condições contextuais, ou seja, o perfil dos alunos e as características dos estabelecimentos de ensino. Para estudar essa questão, seja teórica ou empiricamente, é preciso explicitar um modelo conceitual que apresente as várias inter-relações entre os fatores explicativos no resultado final, isto é, o valor do Ideb. Partiuse de um estudo anterior (SOARES, 2007) em que se propôs um modelo conceitual para o 
desempenho do aluno, adaptando-o para a unidade escolar à qual se refere o Ideb.

No modelo anterior, assume-se que o desempenho está relacionado às características de cada aluno, as quais interagem com as estruturas em que ele está inserido: a família, a escola e a sociedade. 0 teste empírico do modelo depende de abordagem multidisciplinar que agregue conhecimentos da psicologia, da educação, da sociologia, da economia e inclusive da ciência política, em muitos momentos subsidiados pela coleta e pela análise de dados por meio de técnicas estatísticas apropriadas.

Na adaptação do modelo ao problema desta pesquisa, consideraram-se as dimensões escolares que pudessem ser aferidas empiricamente com os dados disponíveis. Assim, a medida do Ideb de cada escola pública provém do banco de dados disponibilizado pelo Inep. Os fatores associados aos alunos que potencialmente influenciam o resultado do Ideb são provenientes de avaliações em larga escala cujos detalhes serão descritos a seguir. Foram considerados os fatores que influem no contexto escolar, configurando o que a literatura educacional denomina como efeito dos pares (WILLMS; SOMERS, 2001). São eles: o nível socioeconômico médio de cada escola e a proporção de alunos discriminados por raça/cor e também por gênero.

Dentre os fatores dos alunos, não se levou em conta o atraso escolar médio dos matriculados, isto é, a diferença entre a média de idade em relação ao que seria esperado para a série. Normalmente, o atraso escolar deve ser considerado nos estudos sobre desempenho escolar devido ao seu efeito deletério nos resultados; entretanto, tal atraso já está composto no cálculo do Ideb, no termo referente ao rendimento médio da escola calculado a partir de suas respectivas taxas de aprovação. Assim, seria incorreto considerá-lo também como um fator explicativo.

Para a caracterização das escolas, foram construídos fatores associados aos construtos teóricos, a partir das informações do Censo Escolar. São eles: infraestrutura, tamanho e complexidade da escola. Optou-se por desenvolver tais fatores em vez de se utilizar os itens específicos para evitar interpretações de que características isoladas das escolas podem ser reificadas para a melhoria da educação. Os detalhes desses fatores serão descritos a seguir.

Optou-se também por não incluir fatores associados aos professores, embora eles façam parte do modelo conceitual adaptado para este trabalho. Ocorre que, no Censo Escolar, as informações sobre professores se referem à função docente, uma concepção mais abstrata que não se vincula a apenas uma escola ou uma turma de alunos. A Prova Brasil possui informações mais detalhadas sobre os professores (formação, experiência e condições de trabalho), coletadas por meio de questionário. Contudo, há dificuldades para o uso desses dados de forma agregada por escola. $\mathrm{Na}$ base de dados, há muitos questionários não respondidos, e a ausência de informações reduz os casos válidos nos modelos estatísticos de análise. Além disso, o uso de informações individuais sobre os professores no nível da escola pode gerar problemas de agregação em grau diferente do que ocorre quando se faz o mesmo com as informações dos alunos. Enquanto estes últimos contam em número de pelo menos uma dezena por escola para se produzir a média de um fator de interesse, no caso dos professores, as informações quase sempre se referem a apenas um ou dois indivíduos.

\section{Explicação dos fatores}

\section{- Nível socioeconômico da escola}

0 contexto socioeconômico das escolas é o fator mais importante para análise de resultados educacionais. Espera-se, portanto, que uma escola que atende a alunos com maior poder aquisitivo e com mais recursos culturais atinja valores mais altos do Ideb. Tal fator foi obtido em um estudo externo a este, cuja finalidade específica foi produzir uma medida de nível socioeconômico médio para todas as escolas brasileiras (ALVES; SOARES, 
2012). Para isso, foram utilizados dados de várias pesquisas educacionais realizadas pelo Inep na educação básica junto a escolas públicas e privadas. Itens dos questionários respondidos pelos alunos nessas avaliações que guardam relação com o construto teórico - a escolaridade e a posição ocupacional dos pais do aluno e a renda familiar (evidenciada pela posse de bens, uso de serviços e rendimento de fontes diversas) - foram agregados em uma única medida do nível socioeconômico do aluno. 0 processo de agregação foi feito com o uso de uma técnica estatística multivariada denominada Teoria da Resposta ao Item (TRI), cujos detalhes estão descritos em um artigo dedicado ao assunto (ALVES; SOARES, 2009). Em seguida, o nível socioeconômico estimado foi agregado pela média do nível socioeconômico dos alunos de cada escola.

\section{- Proporção de alunos discriminados por raça/cor e por gênero}

Estudos com dados das avaliações em larga escala mostram que alunos que se declaram brancos têm desempenho superior em comparação aos alunos que se declaram pardos, pretos, amarelos ou indígenas. As diferenças entre alunos discriminados por cor/raça persistem inclusive dentro das mesmas escolas e com o controle das diferenças socioeconômicas entre alunos e escolas (SOARES; ALVES, 2003). Por isso, considerou-se relevante avaliar se a presença de mais alunos brancos na escola está associada ao valor do Ideb.

A proporção de alunos discriminados por gênero na escola é considerada relevante porque, nos testes aplicados nas avaliações educacionais, os alunos, em geral, têm desempenho melhor em matemática, e as alunas se saem bem melhor em leitura. No Ideb, não há distinção entre esses conteúdos cognitivos, que são sintetizados em uma única medida de desempenho padronizada. Contudo, o processo de padronização das proficiências para o cálculo do Ideb não considera as diferenças interpretativas que existem nas escalas originais de matemática e leitura, o que torna o indicador dominado pela proficiência em matemática. Como explica Soares (2011, p. 7), “o indicador de aprendizado do Ideb assume que os alunos brasileiros sabem mais Matemática do que Leitura”. Assim, considerou-se relevante avaliar se a presença de mais alunos do que alunas na mesma instituição tem associação com o valor do Ideb da escola.

Os dois indicadores - percentual de brancos e de alunos - foram obtidos pela proporção, por escola, dessas categorias nas respectivas variáveis do questionário respondido pelos alunos na Prova Brasil.

\section{- Infraestrutura da escola}

No Brasil, infraestrutura física, equipamentos e conservação do prédio escolar importam. Evidências nesse sentido foram observadas em vários estudos que analisaram dados das avaliações em larga escala conforme uma revisão elaborada por Alves e Franco (2008). Neste trabalho, a medida da infraestrutura da escola foi obtida com base nos dados do Censo Escolar, agregando indicadores de existência de: local próprio de funcionamento da escola, água tratada, energia elétrica, saneamento básico (coleta de lixo, de esgoto e presença de banheiro na escola), outros espaços e recursos escolares (biblioteca, laboratório, cantina, computadores e outros equipamentos eletrônicos). A técnica para a agregação desses itens em um único índice - assim como os seguintes referentes às escolas - é a mesma utilizada para estimar o nível socioeconômico médio.

\section{- Tamanho e complexidade da escola}

0 tamanho da escola - medido pelo número de alunos - também importa. Alunos que estudam em escolas grandes tendem a ter desempenho pior do que alunos de escolas menores ou de tamanho moderado (LEE, 2008). 0 tamanho da escola foi estimado com base 
nas informações do Censo Escolar referentes à quantidade de salas, funcionários, número de turmas e matrículas nas escolas.

Escolas que congregam alunos de diferentes níveis e modalidades de ensino são mais complexas porque necessitam de mais espaço físico, mobiliário e equipamentos adaptados aos alunos de diferentes faixas etárias e necessidades específicas, bem como um número maior de profissionais e apoios variados. A medida da complexidade foi obtida agregando-se os indicadores das modalidades de ensino oferecidas na escola - ensino regular, da creche ao ensino médio, e educação especial nos mesmos níveis - e o número de alunos portadores de necessidades especiais. Com isso, assume-se que a escola é mais complexa se atende a alunos de diferentes etapas e modalidades de ensino, e também se faz mais inclusão.

Esses dois últimos fatores foram inicialmente tratados como índices separados, mas, após os testes iniciais, eles foram agregados em uma única dimensão devido à correlação entre eles.

\section{Análises estatísticas}

0 trabalho utiliza os dados referentes ao Ideb 2009 de todas as escolas públicas. ${ }^{4} 0$ banco de dados divulgado pelo Inep possui informações sobre todas as escolas públicas que participaram da Prova Brasil e que alcançaram o número mínimo exigido de alunos participantes dessa avaliação (no mínimo, 10 alunos ou 50\% dos alunos matriculados na série em escolas menores).

Inicialmente, fez-se uma análise descritiva dos dados para observação das tendências do Ideb e suas relações com os fatores contextuais, que será apresentada em forma de gráficos. Em seguida, foram ajustados modelos de regressão linear múltipla para cada um dos

4- 0 Ideb 2011 foi divulgado quando este texto estava em fase de revisão e, portanto, não haveria tempo para incorporar os dados mais recentes nos modelos analíticos. Além disso, os demais microdados utilizados - da Prova Brasil e do Censo Escolar do mesmo ano - não foram publicados pelo Inep. segmentos escolares. 0 modelo de regressão linear ajustado tem a seguinte expressão:

Ideb2009 $_{i}=\beta 0+\beta_{1}\left(\right.$ MNSE $_{i}+\beta_{2}\left(\%\right.$ brancos $_{i}+\beta_{3}(\% \text { alunos })_{i}$ $+\beta_{4}$ (infraestrutura $)_{i}+\beta_{5}\left(\right.$ complexidade $_{i}+r_{i}$

0 quadro 1 contém a explicação detalhada das covariáveis incluídas no modelo.

Quadro 1 - Variáveis utilizadas nos modelos de análise

\begin{tabular}{|c|c|c|}
\hline Variáveis & Tipo & Descrição \\
\hline \multicolumn{3}{|c|}{ Variável resposta } \\
\hline Ideb 2009 & Contínua & $\begin{array}{l}\text { Índice de Desenvolvimento da Edu- } \\
\text { cação da Escola em 2009. Produto } \\
\text { da média das proficiências padroni- } \\
\text { zadas em matemática e leitura obti- } \\
\text { das na Prova Brasil pelo indicador de } \\
\text { rendimento (o valor médio das taxas } \\
\text { de aprovação da escola) atingido no } \\
\text { Censo Escolar. A escala tem valores } \\
\text { de zero a } 10 \text {. }\end{array}$ \\
\hline \multicolumn{3}{|c|}{ Variáveis explicativas } \\
\hline $\begin{array}{c}\text { MNSE } \\
\text { (Média do nível } \\
\text { socioeconômico } \\
\text { da escola) }\end{array}$ & Contínua & $\begin{array}{l}\text { Medida estimada via Teoria da } \\
\text { Resposta ao Item (TRI) a partir de } \\
\text { informações dos questionários res- } \\
\text { pondidos pelos alunos em avaliações } \\
\text { educacionais do Inep. A escala ori- } \\
\text { ginal foi convertida para valores de } \\
\text { zero a 10. O MNSE refere-se à média } \\
\text { calculada a partir do NSE dos alunos } \\
\text { de cada escola. }\end{array}$ \\
\hline $\begin{array}{l}\% \text { de alunos } \\
\text { brancos }\end{array}$ & Contínua & $\begin{array}{l}\text { Proporção de alunos que se decla- } \\
\text { ram brancos, obtida no questionário } \\
\text { da Prova Brasil. }\end{array}$ \\
\hline $\begin{array}{l}\% \text { de alunos do } \\
\text { sexo masculino }\end{array}$ & Contínua & $\begin{array}{l}\text { Proporção de alunos do sexo mascu- } \\
\text { lino, obtida no questionário da Prova } \\
\vdots\end{array}$ \\
\hline $\begin{array}{c}\text { Infraestrutura da } \\
\text { escola }\end{array}$ & Contínua & $\begin{array}{l}\text { Medida obtida via TRI a partir de in- } \\
\text { formações do Censo Escolar. A esca- } \\
\text { la original foi convertida para valores } \\
\quad \\
\quad \text { de zero a } 10 .\end{array}$ \\
\hline $\begin{array}{c}\text { Complexidade da } \\
\text { escola }\end{array}$ & Contínua & $\begin{array}{l}\text { Medida obtida via TRI a partir de } \\
\text { informações do Censo Escolar. A } \\
\text { escala final é o produto das escalas } \\
\text { parciais de complexidade e de ta- } \\
\text { manho, convertidas para valores de } \\
\text { zero a } 10 \text {. }\end{array}$ \\
\hline
\end{tabular}


A escolha desta abordagem analítica se justifica porque a questão de pesquisa consiste em verificar se há, nas escolas, associação entre uma variável resposta - isto é, o Ideb 2009 - e um conjunto de variáveis explicativas referentes às características do alunado (MNSE, \% \%rancos , $_{i}$ \%alunos ${ }_{i}$ ) e das escolas (infraestrutura e complexidade $_{\mathrm{i}}$ ). Sabe-se, entretanto, que a associação entre uma variável resposta e qualquer covariável depende de quais outras variáveis estão incluídas no modelo. Por exemplo, a associação entre o Ideb 2009 e o MNSE $_{\mathrm{i}}$ depende das outras variáveis incluídas no modelo de regressão e, portanto, utilizadas para o cálculo da associação. Sendo assim, a resposta à questão de pesquisa implica escolher adequadamente as covariáveis do modelo de regressão.

Outro aspecto importante a se destacar é que não faria sentido incluir, no ajuste do modelo, o Ideb do ciclo anterior como covariável, uma vez que os valores do Ideb 2009 e do Ideb 2007 são altamente associados. As escolas não mudam tanto em dois anos. A presença do Ideb anterior no modelo de regressão impediria que as covariáveis consideradas mostrassem sua correlação com o Ideb 2009, pois esta estaria completamente subsumida na correlação entre os dois indicadores (Ideb 2009 e Ideb 2007). Se, entretanto, a questão desta pesquisa fosse descrever ou mesmo prever o comportamento do Ideb de uma escola, a estratégia de análise seria outra. Nesse caso, usar o Ideb do ciclo anterior uma variável já conhecida e altamente associada ao Ideb do ciclo seguinte - é muito melhor do que usar simplesmente $\operatorname{MNSE}_{\mathrm{i}}$, \%brancos, \%alunos , infraestrutura $_{i}$ e complexidade c $_{i}$ que são variáveis apenas indiretamente associadas à variável resposta. $0 u$ seja, diferentes questões exigem diferentes modelos.

\section{Resultados}

A tabela 1 sintetiza as estatísticas descritivas das variáveis incluídas nos modelos de regressão. Nota-se a discrepância entre os valores do Ideb do primeiro e do segundo segmento do ensino fundamental, o que sugere problemas muito distintos nas duas etapas escolares.

Tabela 1 - Estatísticas descritivas das variáveis

Séries iniciais do ensino fundamental

\begin{tabular}{|c|c|c|c|c|c|}
\hline & $\mathrm{N}$ & Mínimo & Máximo & Média & $\begin{array}{l}\text { Desvio- } \\
\text { padrão }\end{array}$ \\
\hline Ideb $2009\left(^{\star}\right)$ & 43.400 & 0,20 & 9,00 & 4,35 & 1,10 \\
\hline MNSE & 43.392 & 1,05 & 7,77 & 4,66 & 0,79 \\
\hline $\begin{array}{l}\text { \% de alunos do } \\
\text { gênero masculino }\end{array}$ & 43.349 & 0,00 & 100,00 & 51,36 & 8,98 \\
\hline $\begin{array}{l}\% \text { de alunos } \\
\text { brancos }\end{array}$ & 43.349 & 0,00 & 100,00 & 34,45 & 17,63 \\
\hline $\begin{array}{l}\text { Infraestrutura da } \\
\text { escola }\end{array}$ & 43.184 & 0,00 & 10,00 & 6,62 & 1,48 \\
\hline Complexidade & 43.184 & 0,00 & 10,00 & 4,05 & 1,54 \\
\hline $\begin{array}{l}\text { Número de escolas } \\
\text { no modelo }\end{array}$ & 33.042 & - & - & - & - \\
\hline
\end{tabular}

Séries finais do ensino fundamental

\begin{tabular}{|c|c|c|c|c|c|}
\hline & N & Mínimo & Máximo & Média & $\begin{array}{l}\text { Desvio- } \\
\text { padrão }\end{array}$ \\
\hline Ideb $2009\left(^{*}\right)$ & 31.781 & 0,70 & 8,00 & 3,68 & 0,85 \\
\hline MNSE & 31.636 & 0,91 & 8,20 & 4,67 & 0,90 \\
\hline $\begin{array}{l}\% \text { de alunos do } \\
\text { gênero masculino }\end{array}$ & 31.760 & 0,00 & 100,00 & 45,72 & 9,74 \\
\hline $\begin{array}{l}\% \text { de alunos } \\
\text { brancos }\end{array}$ & 31.760 & 0,00 & 100,00 & 33,27 & 20,10 \\
\hline $\begin{array}{l}\text { Infraestrutura da } \\
\text { escola }\end{array}$ & 31.685 & 0,00 & 10,00 & 7,24 & 1,32 \\
\hline Complexidade & 31.685 & 0,24 & 10,00 & 5,42 & 1,51 \\
\hline $\begin{array}{l}\text { Número de escolas } \\
\text { no modelo }\end{array}$ & 24.734 & - & - & - & - \\
\hline
\end{tabular}

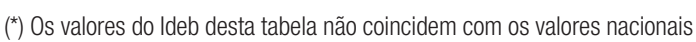
divulgados no site do Inep porque as médias do país incluem o ldeb médio do conjunto das escolas particulares calculado com os dados do Saeb.

Fonte: Elaboração própria a partir de dados da Prova Brasil, do Censo Escolar e do Ideb (Inep/MEC). 
Os gráficos de caixas de número 1 a 10 descrevem as medidas de tendência central e de variabilidade do Ideb segundo os fatores considerados. A linha pontilhada representa a média do Ideb de todas as escolas. ${ }^{5}$ Alguns destaques podem ser feitos em relação ao conjunto dos gráficos.

Primeiro, observa-se em todos eles a grande dispersão dos valores médios do Ideb. Por exemplo, no gráfico 1, que compara os subconjuntos de escolas discriminadas pelos quartis da média do nível socioeconômico (MNSE), nota-se uma relação positiva, ou seja, escolas nos quartis de MNSE mais baixos tendem a apresentar valores igualmente mais baixos do Ideb e, ao contrário, escolas nos quartis mais altos têm valores mais altos do Ideb. Mas há uma grande variabilidade na distribuição. Destacam-se os muitos casos extremos (simbolizados pelos pequenos círculos), o que significa que há escolas com MNSE mais baixos, mas com valores do Ideb em nível muito alto, e também o contrário. Além disso, registram-se

Gráfico 1 - Média do Ideb 2009 (séries iniciais) por quartil do MNSE

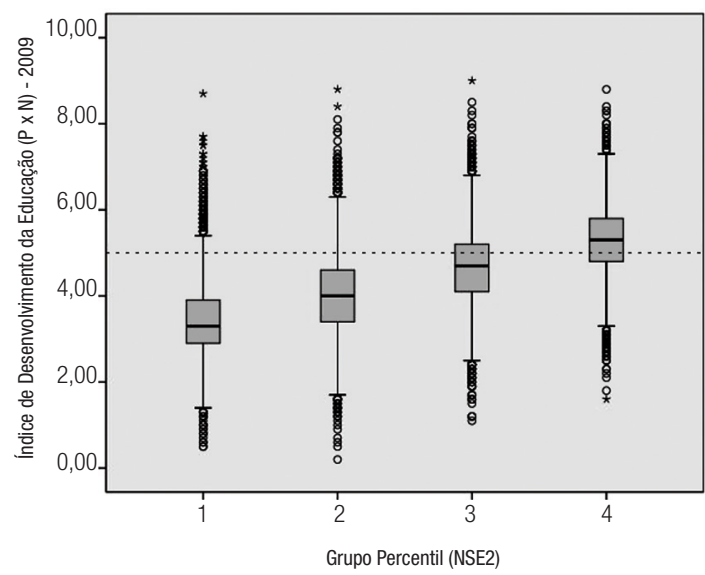

Fonte: Elaboração própria a partir de dados do Inep (Censo Escolar).

5- As caixas e as linhas mostram a tendência central (mediana, assinalada pela linha que divide a caixa) e a variabilidade (a distância de uma ponta à outra). Além disso, indicam os casos cujos valores as ocorrências de escolas com valores de Ideb muito extremos (simbolizados pelos asteriscos) para o subgrupo de MNSE em que se encontram. Esses casos totalmente atípicos merecem estudos adicionais.

Uma segunda observação diz respeito aos valores de Ideb tendencialmente muito mais baixos nos anos finais do ensino fundamental em todos os subgrupos. A elevação da média desse nível de ensino parece estar associada principalmente aos poucos casos extremos, enquanto a maioria das escolas têm valores do Ideb que podem ser considerados muito baixos.

Por último, notam-se fatores que não mostram relações muito claras com o Ideb nas análises univariadas descritas nos gráficos. Em alguns gráficos, observa-se maior contraste entre o subgrupo inferior em comparação com o subgrupo superior, mas mesmo essa observação varia entre os níveis de ensino. Na sequência, serão descritos os resultados dos modelos de análise para se verificarem as relações observadas de forma simultânea.

Gráfico 2 - Média do Ideb 2009 (séries finais) por quartil do MNSE



Fonte: Elaboração própria a partir de dados do Inep (Censo Escolar).

extrapolam a distribuição de forma extrema (assinalados com círculos) ou muito extrema (asteriscos) 
Gráfico 3 - Média do Ideb 2009 (séries iniciais) por quartil de proporção de alunos brancos

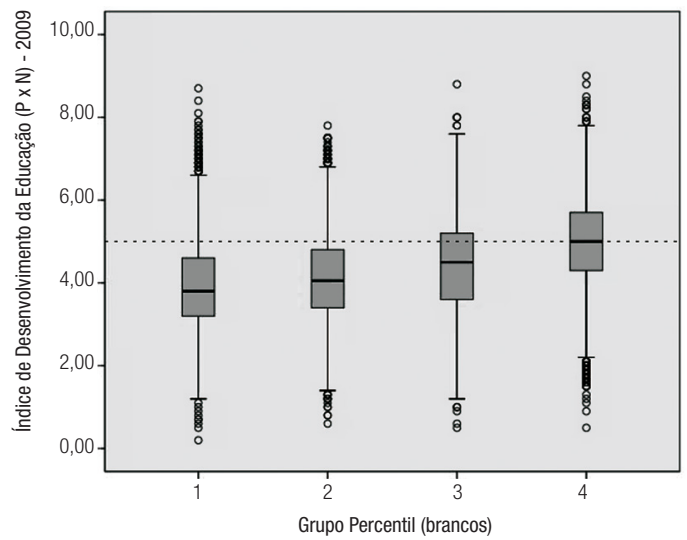

Fonte: Elaboração própria a partir de dados do Inep (Censo Escolar).

Gráfico 5 - Média do Ideb 2009 (séries iniciais) por quartil de alunos do gênero masculino

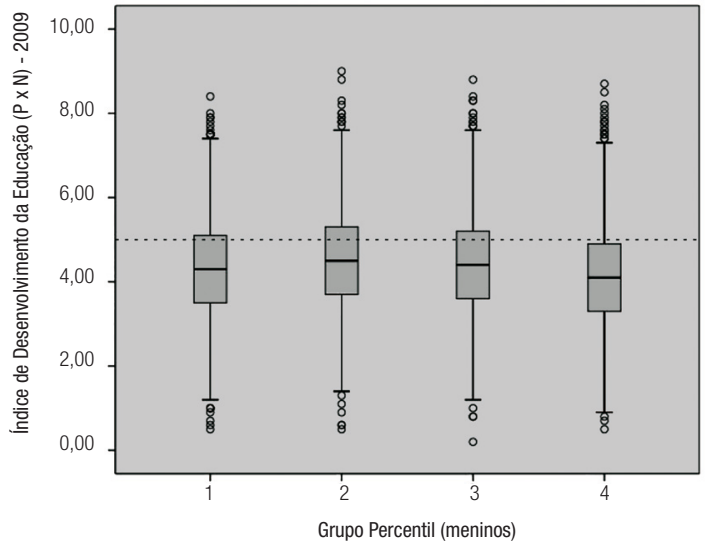

Fonte: Elaboração própria a partir de dados do Inep (Censo Escolar).

Gráfico 7 - Média do Ideb 2009 (séries iniciais) por quartil de infraestrutura da escola

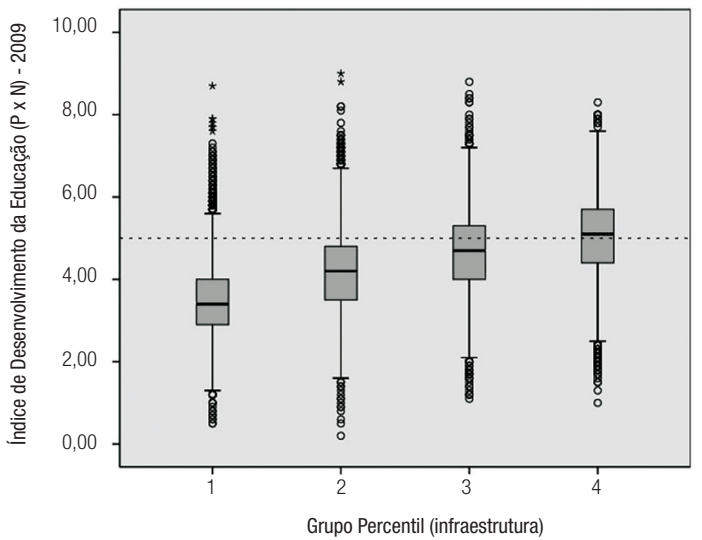

Fonte: Elaboração própria a partir de dados do Inep (Censo Escolar).
Gráfico 4 - Média do Ideb 2009 (séries finais) por quartil de proporção de alunos brancos

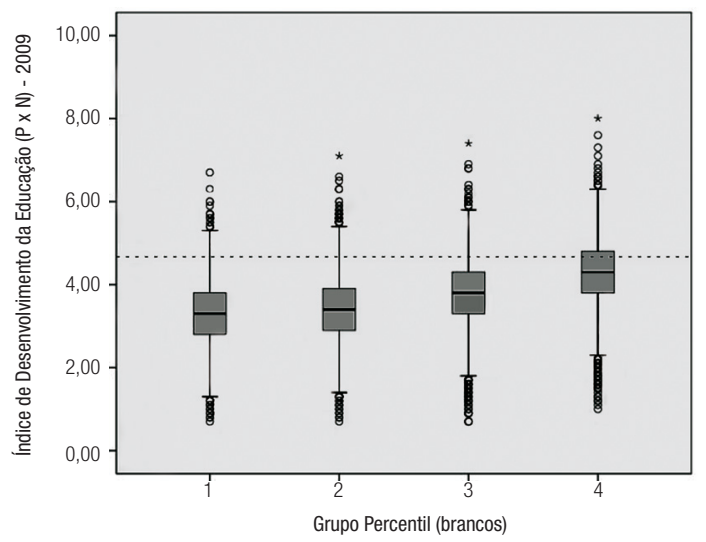

Fonte: Elaboração própria a partir de dados do Inep (Censo Escolar).

Gráfico 6 - Média do Ideb 2009 (séries finais) por quartil de alunos do gênero masculino

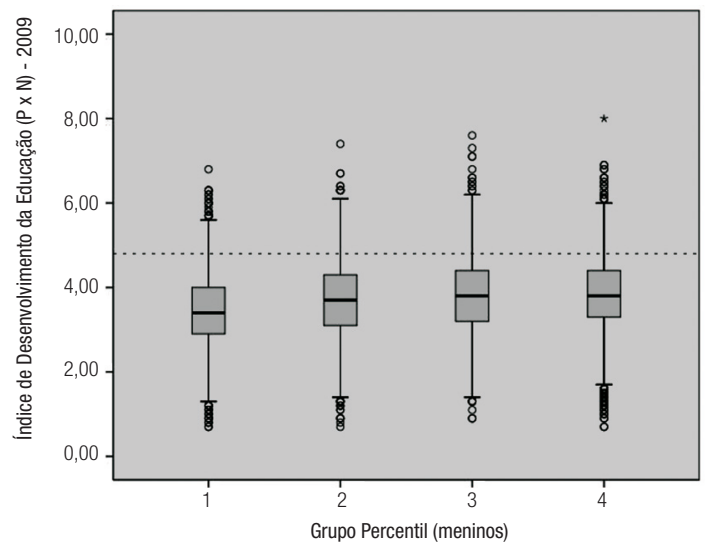

Fonte: Elaboração própria a partir de dados do Inep (Censo Escolar).

Gráfico 8 - Média do Ideb 2009 (séries finais) por quartil de infraestrutura da escola

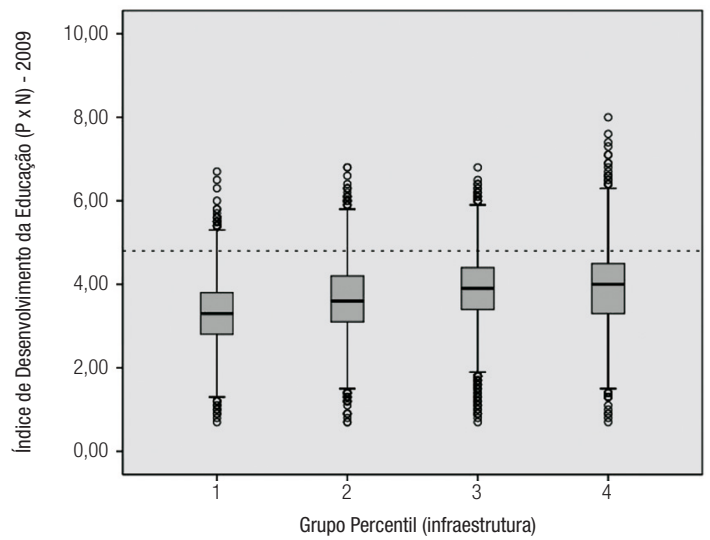

Fonte: Elaboração própria a partir de dados do Inep (Censo Escolar). 
Gráfico 9 - Média do ldeb 2009 (séries iniciais) por quartil de complexidade $\mathrm{x}$ tamanho da escola

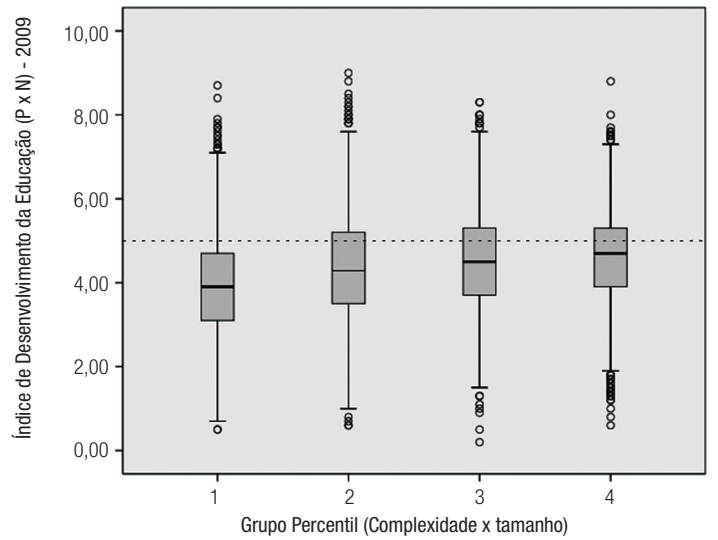

Fonte: Elaboração própria a partir de dados do Inep (Censo Escolar).

A tabela 2 apresenta os resultados do ajuste dos modelos de regressão linear múltipla para séries iniciais e séries finais do ensino fundamental. Destacam-se algumas tendências. Os valores dos coeficientes ( $\beta$ ) e dos coeficientes padronizados (Beta) são em geral baixos, embo-
Gráfico 10 - Média do Ideb 2009 (séries finais) por quartil de complexidade $\mathrm{x}$ tamanho da escola

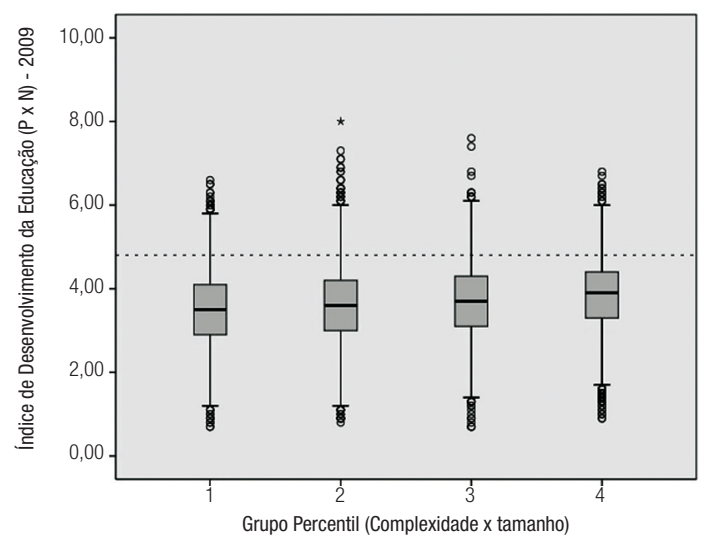

Fonte: Elaboração própria a partir de dados do Inep (Censo Escolar).

ra todos sejam significativos. Na escala do Ideb, devido à sua concepção metodológica, um incremento de poucos décimos no indicador pode significar uma mudança substantiva em seu patamar (Cf. SOARES, 2011). Portanto, valores tão pequenos não devem ser negligenciados.

Tabela 2 - Modelo de regressão linear múltipla para o ldeb 2009 (séries iniciais e séries finais do ensino fundamental)

\begin{tabular}{|c|c|c|c|c|c|c|}
\hline \multirow{2}{*}{ Variáveis } & \multicolumn{3}{|c|}{$\begin{array}{c}\text { Ideb } 2009 \\
5^{\circ} \text { ano }\end{array}$} & \multicolumn{3}{|c|}{$\begin{array}{c}\text { Ideb } 2009 \\
9^{\circ} \text { ano }\end{array}$} \\
\hline & $\mathrm{B}$ & Beta & Sig. & $\mathrm{B}$ & Beta & Sig. \\
\hline (Constante) & 0,19 & & 0,00 & 1,44 & & 0,00 \\
\hline MNSE & 0,70 & 0,50 & 0,00 & 0,34 & 0,36 & 0,00 \\
\hline \% de alunos do gênero masculino & $-0,01$ & $-0,04$ & 0,00 & 0,01 & 0,06 & 0,00 \\
\hline$\%$ de alunos brancos & 0,01 & 0,08 & 0,00 & 0,01 & 0,24 & 0,00 \\
\hline Infraestrutura & 0,17 & 0,22 & 0,00 & 0,03 & 0,04 & 0,00 \\
\hline Complexidade & $-0,03$ & $-0,05$ & 0,00 & $-0,03$ & $-0,05$ & 0,00 \\
\hline $\mathrm{R}^{2}$ & & 0,47 & & & 0,31 & \\
\hline
\end{tabular}

Fonte: Elaboração própria a partir de dados da Prova Brasil, do Censo Escolar e do Ideb (Inep/MEC).

Os resultados evidenciam que o Ideb da escola é fortemente associado ao nível socioeconômico médio de seus alunos, mesmo com o controle dos fatores considerados em relação à escola. Outros fatores do aluno também têm impacto significativo no Ideb, porém em magnitude bem menor. A maior proporção de alunos brancos faz diferença, mas, nesse caso, a associação é maior nas séries finais. Tal resultado indica que a seletividade no segundo segmento do ensino fundamental - devido aos problemas de reprovação e abandono precoce da escola - afeta mais os alunos não brancos. A maior proporção de alunos nas séries iniciais do ensino fundamental em comparação com as alunas tem impacto negativo, mas, nas séries fınais, a associação opera em sentido contrário. Em ambos os casos, os valores dos coeficientes, embora significativos, são mínimos.

Entre os fatores das escolas, destaca-se o impacto positivo da infraestrutura, principalmente nas séries iniciais. Para facilitar o 
entendimento desse resultado, vamos imaginar dois estabelecimentos de ensino hipotéticos chamados de A e B. Os dois estabelecimentos atendem aos anos iniciais do ensino fundamental, possuem características semelhantes quanto ao nível socioeconômico dos alunos (por exemplo, na média da escala, cujo valor é $4,7)$ e os outros fatores associados aos alunos apresentam valores constantes e neutros. A escola A possui uma infraestrutura ideal (valor igual a 10). Com isso, ela poderia atingir um Ideb de 5,4, valor acima da média nacional em 2009. A escola B, com infraestrutura bem pior (por exemplo, com valor igual a 1), teria um Ideb de 3,5. Vale ressaltar que na escala do Ideb a diferença entre essas duas escolas hipotéticas é enorme.

Se o exercício fosse aplicado a dois estabelecimentos de ensino dos anos finais do ensino fundamental, a diferença não seria tão grande. Essa análise sugere que uma mesma infraestrutura que parece adequada para os anos iniciais do ensino fundamental pode não ser suficiente para os anos finais.

0 fator complexidade da escola tem um efeito negativo e equivalente nos dois níveis de ensino. Esse resultado pode refletir o desempenho das escolas menores localizadas em pequenos municípios do interior do país e que têm valores do Ideb acima da média nacional (PADILHA et al., 2012). Aplicando o valor do coeficiente ao exemplo hipotético descrito, a escola A, se fosse mais complexa - isto é, um estabelecimento grande, com muitos alunos, funcionários e com atendimento a vários níveis e tipos de alunos -, teria o Ideb reduzido para 5,1, enquanto a escola B teria seu Ideb reduzido para 3,2. A evidência é que, no ensino fundamental, é melhor estudar em estabelecimentos menores e/ou com atendimento menos diversificado.

\section{Discussão}

Este trabalho analisou o Ideb da escola considerando, simultaneamente, alguns fatores que potencialmente impactam seu valor. 0 estudo foi motivado pelo reconhecimento de que o uso intensivo e disseminado do indicador não autoriza sua redução a apenas um ranking entre escolas e sistemas de ensino. 0 Ideb, inegavelmente, conquistou legitimidade na atual conjuntura, haja vista sua incorporação no texto do Plano Nacional da Educação (PNE) para o presente decênio. Isso desafia a pesquisa educacional a ampliar sua influência no debate público que gira em torno desse tema com base em argumentos fundamentados. Entretanto, o uso unidimensional do Ideb, ou seja, a divulgação de seu valor bruto sem a consideração das condições contextuais das escolas, é o que prevalece no uso público do indicador. Nesse sentido, o trabalho corrobora o esforço de outros estudos empíricos no sentido de desvelar as condições para se atingir a qualidade educacional aferida pelo Ideb e por outros indicadores do mesmo tipo.

Procurou-se demonstrar, a partir dos dados empíricos, que as escolas devem ser vistas pelo aprendizado de seus alunos - a expressão da efetivação de sua função social -, mas também pelas condições contextuais para obtenção desses resultados. Um sistema educacional só pode ser dito de qualidade se suas desigualdades são também consideradas na análise de seu desempenho. Os resultados descritos na seção anterior evidenciaram que a síntese da qualidade da escola em um único número não contempla as condições desiguais entre os estabelecimentos de ensino.

Entre os fatores analisados neste trabalho, o maior impacto no Ideb, como esperado e compatível com a literatura da área educacional, é a composição do grupo de alunos matriculados no estabelecimento de ensino. Para escolas que congregam mais alunos com condições socioeconômicas desfavoráveis, é muito mais difícil atingir as metas associadas ao Ideb. ${ }^{6}$ Entretanto, esse fator só mudará na medida em que políticas sociais tenham sucesso.

6- 0 impacto do nível socioeconômico prevalece mesmo quando se considera, em modelos preditivos, o Ideb do ciclo anterior. Tal resultado não está exposto neste trabalho, mas foi constatado em modelos preditivos testados no escopo do programa de pesquisa que resultou neste artigo. 
Quanto aos demais fatores do aluno (gênero masculino e cor/raça branca), os impactos relativos no Ideb são muito pequenos, embora significativos. A indicação é de que há maior seletividade racial ao longo do ensino fundamental e de que, no segundo segmento, a maior proporção de alunos em relação às alunas está associada ao Ideb médio mais elevado. Contudo, nesse caso, é preciso investigar se a forma como o Ideb é calculado - com a superestimação da proficiência em matemática, área em que os meninos se saem melhor no Saeb (SOARES, 2011) - pode ter relação com esse resultado. Há necessidade, portanto, de estudos adicionais sobre os fatores raça/cor e gênero, sobretudo em modelos com dados agregados.

As condições de infraestrutura e de complexidade da escola - medidas com os dados do Censo Escolar - também guardam relação significativa com o Ideb. Para terem seu direito educacional atendido, os alunos que trazem menos de casa precisam de escolas com melhor infraestrutura e mais focadas em suas necessidades de aprendizado. Nas séries iniciais do ensino fundamental, o efeito da infraestrutura da escola no Ideb é bem maior do que nas séries fınais. Uma possível explicação é que quanto mais se avança no sistema escolar e na idade dos alunos, mais as escolas precisam oferecer. A mesma infraestrutura que atende razoavelmente aos anos iniciais da escolarização parece não ter efeito equivalente no segmento seguinte, que envolve mais disciplinas escolares, mais professores especialistas e uma geração bem mais exigente e diversificada. Essa hipótese, entretanto, deveria ser também verificada a partir de outras pesquisas. 0 impacto da complexidade da escola ainda é pouco estudado, mas os resultados indicam que as escolas mais complexas - ou seja, os estabelecimentos maiores e que atendem a mais níveis e modalidades de ensino - implicam complicações adicionais para as escolas atingirem um Ideb mais alto.

Uma reflexão sólida para a superação das limitações das escolas é o indicador Custo Aluno/Qualidade Inicial (CAQi), que aponta a necessidade de que todos os estabelecimentos de ensino tenham patamares de recursos compatíveis com as necessidades de aprendizado de seus alunos (CARREIRA; PINTO, 2007). Embora não tenha sido possível incluir na análise empírica a questão dos docentes - por limitação dos dados utilizados no trabalho -, teoricamente fica claro que isso também é necessário.

Os resultados deste estudo, do ponto de vista metodológico, sugerem a necessidade da busca de um consenso em duas temáticas. Em primeiro lugar, diante da grande variação de resultados dos alunos dentro de cada escola, o uso da média da Prova Brasil e da taxa de aprovação nos segmentos escolares para o cálculo do Ideb tem como consequência o desaparecimento da variação dos indicadores originais entre os alunos. Na literatura educacional, há muitos estudos que mostram a possibilidade de viés quando se utiliza a escola como unidade de análise. Para lidar com essa situação foram desenvolvidos os modelos hierárquicos nos quais o aluno é a unidade de análise, mantendo-se a escola como unidade de intervenção e possibilitando-se, assim, o estudo do efeito escola. Idealmente, esses modelos deveriam sempre ser utilizados para estudos educacionais. Para o problema em tela, tomar-se-iam duas condições do aluno como resposta: seu rendimento, ou seja, sua situação de aprovação, abandono ou reprovação (dado obtido com o Censo Escolar), e seu desempenho, medido pelas proficiências na Prova Brasil. Dessa forma, seria possível uma análise mais fina da qualidade educacional quanto ao rendimento e ao desempenho dos alunos em vez de uma síntese na média da escola, que pode ser inflada pela melhora apenas de um desses dois elementos. Mas, para isso, seria necessário que a Prova Brasil e o Censo Escolar fossem compatíveis no nível do aluno, e não apenas no nível da escola, o que ainda não é possível.

Em segundo lugar, este estudo convida à organização de investigações com desenho metodológico misto, nos quais escolas com valores extremos de rendimento e desempenho 
- identificados pelos resíduos positivos ou negativos dos modelos de regressão - seriam investigadas a partir de metodologias qualitativas. Isso já foi feito em algumas ocasiões em alguns Estados do Brasil (ABRUCIO, 2010; VIDAL; VIEIRA, 2011) e merece continuidade.
Fica claro, portanto, que as políticas públicas para a educação brasileira exigem o estudo dos dados existentes de forma muito mais ampla do que apenas sua síntese em um indicador como o Ideb, assim como a aproximação de metodologias provenientes de epistemologias distintas.

\section{Referências}

ABRUCIO, Fernando Luiz. Gestão escolar e qualidade da educação: um estudo sobre dez escolas paulistas. Estudos \& Pesquisas Educacionais, São Paulo, v. 1, p. 241-274, 2010.

ALMEIDA, Ana Maria F. 0 assalto à educação pelos economistas. Tempo Social, São Paulo, v. 20, p. 163-178, 2008.

ALVES, Maria Teresa Gonzaga; FRANCO, Creso. A pesquisa em eficácia escolar no Brasil: evidências sobre o efeito das escolas e fatores associados à eficácia escolar. In: BROOKE, Nigel; SOARES, José Francisco (Eds.). Pesquisa em eficácia escolar: origem e trajetórias. Belo Horizonte: Editora UFMG, 2008. p. 482-500.

ALVES, Maria Teresa Gonzaga; SOARES, José Francisco. Medidas de nível socioeconômico em pesquisas sociais: uma aplicação aos dados de uma pesquisa educacional. Opinião Pública, Campinas, v. 15, n. 1, p. 1-30. 2009.

Medida de nível socioeconômico de alunos e escolas com as informações das avaliações educacionais em larga escala. Trabalho aceito para apresentação no $36^{\circ}$ Encontro Anual da Associação Nacional de Pós-Graduação e Pesquisa em Ciências Sociais, Águas de Lindoia, 21 a 25 de outubro de 2012.

BONAMINO, Alícia; FRANCO, Creso. Avaliação e política educacional: o processo de institucionalização do SAEB. Cadernos de Pesquisa, São Paulo, n. 108, p. 101-132, 1999.

BONAMINO, Alicia; SOUSA, Sandra Zákia. Três gerações de avaliação da educação básica no Brasil: interfaces com o currículo da/ na escola. Educação e Pesquisa, São Paulo, v. 38, n. 2, p. 373-388, 2012.

BOURDIEU, Pierre; PASSERON, Jean-Claude. A reprodução: elementos para uma teoria do sistema de ensino. Petrópolis: Vozes, 2008.

BRASIL. Decreto ñ 6.064, de 24 de abril de 2007. Dispõe sobre a implementação do Plano de Metas Compromisso Todos pela Educação, pela União Federal, em regime de colaboração com Municípios, Distrito Federal e Estados, e a participação das famílias e da comunidade, mediante programas e ações de assistência técnica e financeira, visando a mobilização social pela melhoria da qualidade da educação básica. Diário Oficial da União, Brasília, 24 abr. 2007.

. Projeto de Lei do Plano Nacional de Educação (PNE) para vigorar de 2011 a 2020. Texto enviado pelo Governo Federal ao Congresso. Brasília: Ministério da Educação, 15 dez. 2010.

BROOKE, Nigel; CUNHA, Maria Amália. A avaliação externa como instrumento da gestão educacional nos estados. Estudos \& Pesquisas Educacionais, São Paulo, v. 2, p. 17-79, 2011. Disponível em: <http://www.fvc.org.br/estudos-e-pesquisas/ livro-2-2011.shtml>. Acesso em 20 dez. 2012.

BRYK, Antony S.; LEE, Valerie. A multilevel model of social distribution of high school. In: DARLING-HAMMOND, Linda (Ed.). Review of research in education. Washington: American Education Research Association, 1989. p. 171-267.

CARREIRA, Denise; PINTO, José Marcelino Resende. Custo aluno-qualidade inicial: rumo à educação pública de qualidade no Brasil. São Paulo: Global, 2007. 
COLEMAN, James et al. Equality of educational opportunity. Washington: U.S. Department of Health, Education, and Welfare, 1966.

COTTA, Tereza Cristina. Avaliação educacional e políticas públicas: a experiência do Sistema Nacional de Avaliação da Educação Básica (Saeb). Revista do Serviço Público, Brasília, v. 52, n. 4, p. 89-111, 2001.

DUBET, François. 0 que é uma escola justa? Cadernos de Pesquisa, São Paulo, v. 34, p. 539-555, 2004.

ÉRNICA, Maurício; BATISTA, Antônio Augusto Gomes. Educação em territórios de alta vulnerabilidade social na metrópole: um caso na periferia de São Paulo. São Paulo: CENPEC, nov. 2011. (Informe de Pesquisa, n. 3)

FERNANDES, Reynaldo. Índice de Desenvolvimento da Educação Básica (Ideb). Brasilia: Inep, 2007.

FERNANDES, Reynaldo; GREMAUD, Amaury Patrick. Qualidade da educação: avaliação, indicadores e metas. In: VELOSO, Fernando et al. (Orgs.). Educação básica no Brasil: construindo o país do futuro. Rio de Janeiro: Elsevier, 2009. p. 213-238.

FERRAZ, Cláudio. Sistemas educacionais baseados em desempenho, metas de qualidade e a remuneração de professores. In: VELOSO, Fernando et al. (Orgs.). Educação básica no Brasil: construindo o país do futuro. Rio de Janeiro: Elsevier, 2009. p. 239-257.

FRANCO, Creso et al. Qualidade e equidade em educação: reconsiderando o significado de "fatores intra-escolares". Ensaio: Avaliação e Políticas Públicas em Educação, Rio de Janeiro, v. 15, n. 55, p. 277-298, 2007.

FREITAS, Luiz Carlos de. Eliminaç̧ão adiada: 0 ocaso das classes populares no interior da escola e a ocultação da (má) qualidade do ensino. Educação e Sociedade, Campinas, v. 28, n. 100, p. 965-987, 2007.

GOUVEIA, Andréa Barbosa; SOUZA, Ângelo Ricardo de; TAVARES, Taís Moura. 0 Ideb e as políticas educacionais na região metropolitana de Curitiba. Estudos em Avaliação Educacional, Rio de Janeiro, v. 20, n. 42, p. 45-58, 2009.

LEE, Valerie. Utilização e modelos hierárquicos lineares para estudar contextos sociais. In: BROOKE, Nigel; SOARES, José Francisco (Ed.). Pesquisa em eficácia escolar: origem e trajetórias. Belo Horizonte: Editora UFMG, 2008. p. 273-298.

MACHADO-SOARES, Tufi et al. A gestão escolar e o IDEB da escola. Pesquisa e Debate em Educação, Juiz de Fora, v. 1, n. 1, p. 45-68, 2011.

OLIVEIRA, Romualdo Portela de; ARAÚJO, Gilda Cardoso de. Qualidade do ensino: uma nova dimensão da luta pelo direito à educação. Revista Brasileira de Educação, Rio de Janeiro, n. 28, p. 5-23, 2005.

PADILHA, Frederica et al. As regularidades e exceções no desempenho do Ideb dos municípios. Estudos em Avaliação Educacional, São Paulo, v. 23, n. 51, p. 58-81, 2012.

SEN, Amartya. The idea of justice. Cambridge: Harvard University Press, 2009.

SETUBAL, Maria Alice. Equidade e desempenho escolar: é possível alcançar uma educação de qualidade para todos? Revista Brasileira de Estudos Pedagógicos, Brasília, v. 91, n. 228, p. 345-366, 2010.

SOARES, José Francisco. Measuring cognitive achievement gaps and inequalities. International Journal of Educational Research, v. 45, p. 176-187, 2006.

Melhoria do desempenho cognitivo dos alunos do ensino fundamental. Cadernos de Pesquisa, São Paulo, v. 37, n. 130, p. 135-160, 2007.

Análise dos pressupostos educacionais e estatísticos do Índice de Desenvolvimento da Educação Básica (IDEB). In: ENCONTRO DE PESQUISA EM EDUCAÇÃO DA REGIÃO SUDESTE, 10., 2011, Rio de Janeiro. Anais... Rio de Janeiro: ANPED, 2011.

SOARES, José Francisco; ALVES, Maria Teresa Gonzaga. Desigualdades raciais no sistema brasileiro de educação básica. Educação e Pesquisa, São Paulo, v. 29, n. 1, p. 147-165, 2003.

SOUSA, Sandra Zákia; OLIVEIRA, Romualdo Portela de. Sistemas Estaduais de Avaliação: Uso dos Resultados, Implicações e Tendências. Cadernos de Pesquisa, São Paulo, v. 40, n. 141, p. 793-822, 2010. 
TODOS PELA EDUCAÇÃO. Resultados do Ideb com foco na equidade e na qualidade das redes públicas do país: nota técnica dos dados e análises complementares. Disponível em: <http://www.todospelaeducacao.org.br//arquivos/ biblioteca/2010_08_13_documento_tecnico_equidade.pdf>. Acesso em: 5 jun. 2012.

VIDAL, Eloisa Maia; VIEIRA, Sofia Lerche. Gestão educacional e resultados no Ideb: um estudo de caso em dez municípios cearenses. Estudos em Avaliação Educacional, São Paulo, v. 22, p. 419-434, 2011.

WILLMS, Jon Douglas; SOMERS, Marie-A. Family, classroom, and school effects on children's educational outcomes in Latin America. School Effectiveness and School Improvement, v. 12, n. 4, p. 409-445, 2001.

Recebido em: 22.06.2012

Aprovado em: 18.09.2012

Maria Teresa Gonzaga Alves é professora adjunta do Departamento de Ciências Aplicadas à Educação da Faculdade de Educação da Universidade Federal de Minas Gerais e pesquisadora do Grupo de Avaliação e Medidas Educacionais (GAME/ FAE-UFMG).

José Francisco Soares é professor titular aposentado da Faculdade de Educação da Universidade Federal de Minas Gerais e pesquisador do Grupo de Avaliação e Medidas Educacionais (GAME/FAE-UFMG). 